\title{
Generation of 3D Tooth Models Based on Three-dimensional Scanning to Study the Morphology of Permanent Teeth
}

\author{
Generación de Modelos de diente 3D Basados en Escaneo Tridimensional \\ para el Estudio Morfológico de Dientes Permanentes
}

Mario Cantín ${ }^{* * * *}$;. Muñoz ${ }^{* * *, * * * *}$ \& Sergio Olate ${ }^{*, * * * * *}$

CANTÍN, M.; MUÑOZ, M. \& OLATE, S. Generation of 3D tooth models based on three-dimensional scanning to study the morphology of permanent teeth. Int. J. Morphol., 33(2):782-787, 2015.

SUMMARY: The dental student should have thorough knowledge of the dental morphology and develop adequate manual skill to reproduce any part of the tooth, thus maintaining the perfect correlation with associated structures. Computers are becoming an integral part of dental education and dental practice, especially for the acquisition of information in three dimensions and the production of solid objects from computer models. The aim was to present educational material that would allow the dental student to learn to easily identify the morphologic characteristics of permanent teeth, using new technological tools. In order to do this, healthy permanent teeth were scanning by NextEngine ${ }^{\mathrm{TM}} 3 \mathrm{D}$ Scanner HD using the MultiDrive. A $360^{\circ}$ scan in macro range was chosen in each case. The number of scans for this family was 16, due to surface irregularities that require readings from a greater number of angles. Volumes of external structures of the scanned tooth were generated and stored in *.STL files. Virtual models were transferred in to programs used for producing physical prototypes that faithfully reproduce anatomy of interest using ReplicatorG software and MBot Grid II 3D printer. 3D virtual and printed macro models of permanent teeth were obtained. This models allows an excellent visualization of the morphological characteristics of permanent teeth. 3D virtual and printed teeth, derived from real tooth, are intended to be a valuable learning tool that can be used in addition to or instead of extracted teeth and they are anticipated to represent an improvement over plastic teeth.

KEY WORDS: Dental morphology; Permanent teeth; Dental education; 3D scanning; 3D printing; Macro models.

\section{INTRODUCTION}

The knowledge of dental anatomy is fundamental for the practice of any branch of dentistry and form an important part of dental schools' curricula. Although anatomy, in general, seems to be a descriptive and static science, dental anatomy escapes from this rule, because it needs to explain the reason for the existence of dynamic functions of the teeth (Siéssere et al., 2004).

The use of extracted human teeth in dental education remains the optimal basis for the clinical training of dental students in many aspects. However, the difficulties in accessing a sufficient number of suitable extracted teeth for all students, issues with hygiene and the ethical questions involved in using human material for educational purposes without written consent make (de Boer et al., 2013), which is an obstacle to understanding the anatomy.
The external anatomy of teeth should be very well known. Theoretical studies are not enough. The student should study the detailed description of the tooth with copies of them in their hands, and the use of macro models facilitate the assimilation or re-memorization of anatomy because they show all anatomical details that need to be reproduced (Siéssere et al.).

The introduction and development of 3D software, scanning and print techniques enable the visualization and creation of virtual and real anatomical models which give students the opportunity to learn anatomy in detail and train for dental procedures as many times as necessary (Friedland et al., 2008). Additionally, with on-going developments in technology and the increasing availability and use of computer products such as smartphones, tablets and e-books,

CIMA Research Group, Faculty of Dentistry, Universidad de La Frontera, Temuco, Chile.

** Doctoral Program in Morphological Sciences, CEMyQ, Faculty of Medicine, Universidad de La Frontera, Temuco, Chile.

*** Fellow Researcher, Universidad Científica del Sur, Lima, Perú.

***** Center of Research in Biomedical Sciences, Universidad Autónoma de Chile, Temuco, Chile.

****** Division of Oral and Maxillofacial Surgery and CEMyQ, Faculty of Dentistry, Universidad de La Frontera, Temuco, Chile. 
contemporary students are well acquainted with the use of computer technology in everyday life (de Boer et al., 2015).

The aim was to present educational material that would allow the dental student to learn to easily identify the morphologic characteristics of permanent teeth, using new technological tools.

\section{MATERIAL AND METHOD}

The specimen were permanent maxillary and mandibullary tooth extracted from Chilean individuals. A complete dental set was obtained. The specimen had no tooth substance defects or caries. The present study was approved by the Ethics Committee of Universidad de La Frontera (no. 024/15).

The healthy tooth were selected to serve as standard to the generation of virtual models and prototypes. Subsequently, a tooth was placed in a contact scanner NextEngine ${ }^{\mathrm{TM}}$ 3D Scanner HD (NextEngine, Inc., CA, USA) and ScanStudio HD Pro $®$ software, using the MultiDrive hardware, that allows for an object to be rotated around the vertical axis and at different tilts to the vertical axis. This allows for an object to be completely scanned in one scanset. This hardware has an advantage of automatically scanning several scansets without the need to manually reposition the object.

The NextEngine scanner, calibrated at the appropriate resolution, produces high quality surface scans with clearly detectable detail. Each generated virtual surface represents a "mesh", composed of hundreds of thousands of triangles drawn between hundreds of thousands of 3D coordinates. A built-in digital camera captures images of the object, which are mapped onto the mesh, resulting in a texture rendering of the model. Finished models were created using the ScanStudio HD software by placing virtual beads on the same spot in two different scan views.

The scanner mode was set to a resolution of 10,000 points per square inch (associated accuracy=?0.005 inches), while surface texture was recorded as either grayscale or RBG color information with a resolution of 150 dots per inch.

For each tooth, the chosen scanning protocol was $360^{\circ}$ scan (complete revolution of the rotating platform) in macro range (3" x 5" field of view). The number of divisions, or number of scans for this family was 16 , due to surface irregularities that require readings from a greater number of angles. This adds to the scanning time and storage requirements, but not to the resolution of the model. This device generated all outer contours of the tooth for each stroke and from these surfaces, volumes of external structures of the scanned tooth were generated and stored in *.STL files. The scans in each family were aligned and fused; this merged the scans into one solid mesh.

Once the virtual models were generated, they were transferred in to programs used for prototyping by producing physical prototypes that faithfully reproduce anatomy of interest. ReplicatorG is an easy-to-use software in which you can load up 3D designs of the STL format. The program allows to do the following: position, scale and rotate the part, and to convert it into printing instructions (called GCode) and printed in a machine MBot Grid II 3D.

\section{RESULTS}

The procedure described above offers many possibilities for the creation and editing of virtual teeth to be used in a virtual learning environment for dental education.

The creation of a virtual tooth begins by scanning an extracted tooth was successfully. The ScanStudio HD Pro® software uses segmentation algorithms to obtain a 3D visualization. A 3D tooth model was successfully developed and converted to a versatile format using various applications (Fig. 1).

In particular, the properties of general shape and colours of the virtual teeth were considered very similar to those of the extracted teeth.

The faithful reproduction of the the buccal, lingual, palatal, mesial and distal tooth surfaces were achieved in the virtual model. Furthermore, it could scan the entire root outline, including the angles of aplical end. In cases of complex root anatomy, multiradicular teeth, anatomy of each root and interradicular furcal area it was rebuilt (Fig. 2). In a particular case, the mandibular first molar with caries in the buccal groove, reconstruction allowed to maintain the shape of the pit.

Comparing the surfaces of the teeth, including the occlusal surface in molars and premolars, the virtual model representing all the details of each tooth. The occlusal surface could show all the anatomical details of cusps, grooves and pits, reproducing exactly the original anatomy.

Each generated virtual tooth could be printed as a macro model, increased its volume threefold (Fig. 3). 

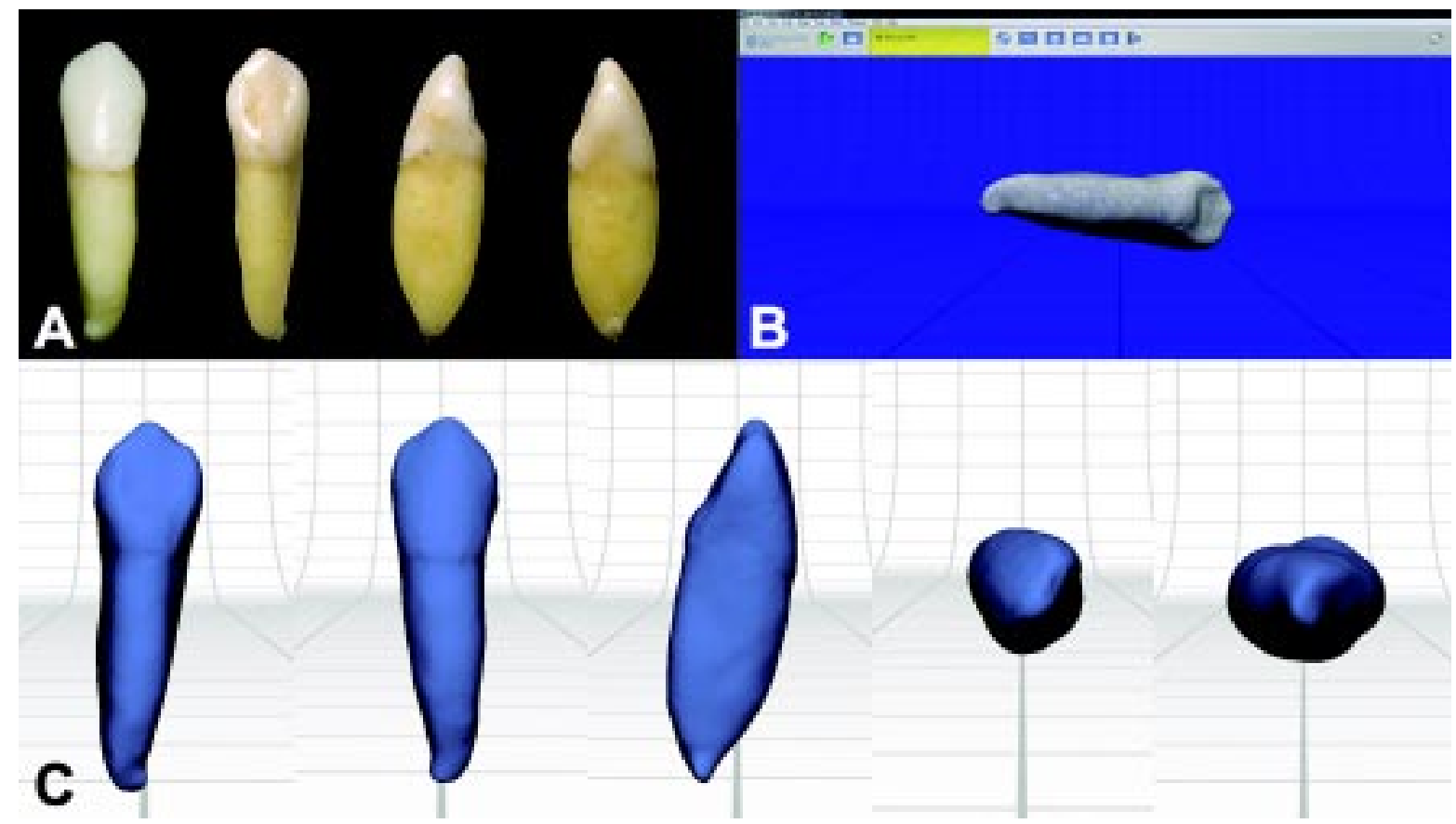

Fig. 1. Single-rooted tooth three-dimensional model. A. Healty canine tooth for scanning. B. ScanStudio HD Pro® representation after smoothing of the data set obtained from the canine tooth. C. Virtual 3D model with different views: lingual, buccal, distal, incisal and apical.

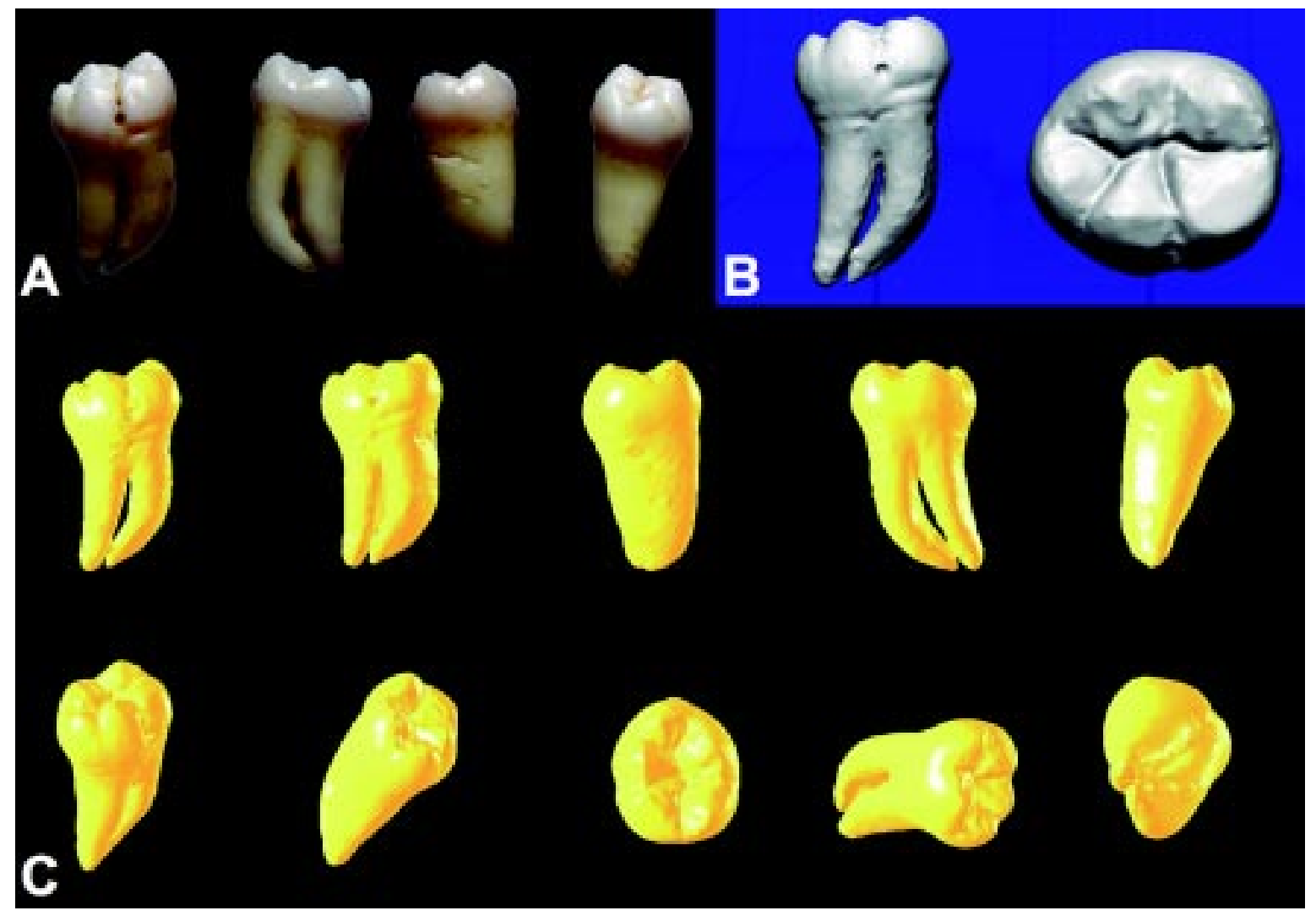

Fig. 2. Multi-rooted tooth three-dimensional model. A. Healty mandibullary first molar tooth for scanning. B. ScanStudio HD Pro® representation after smoothing of the data set obtained from the canine tooth. C. Virtual 3D model with different views by ReplicatorG software prior to GCode generation. 

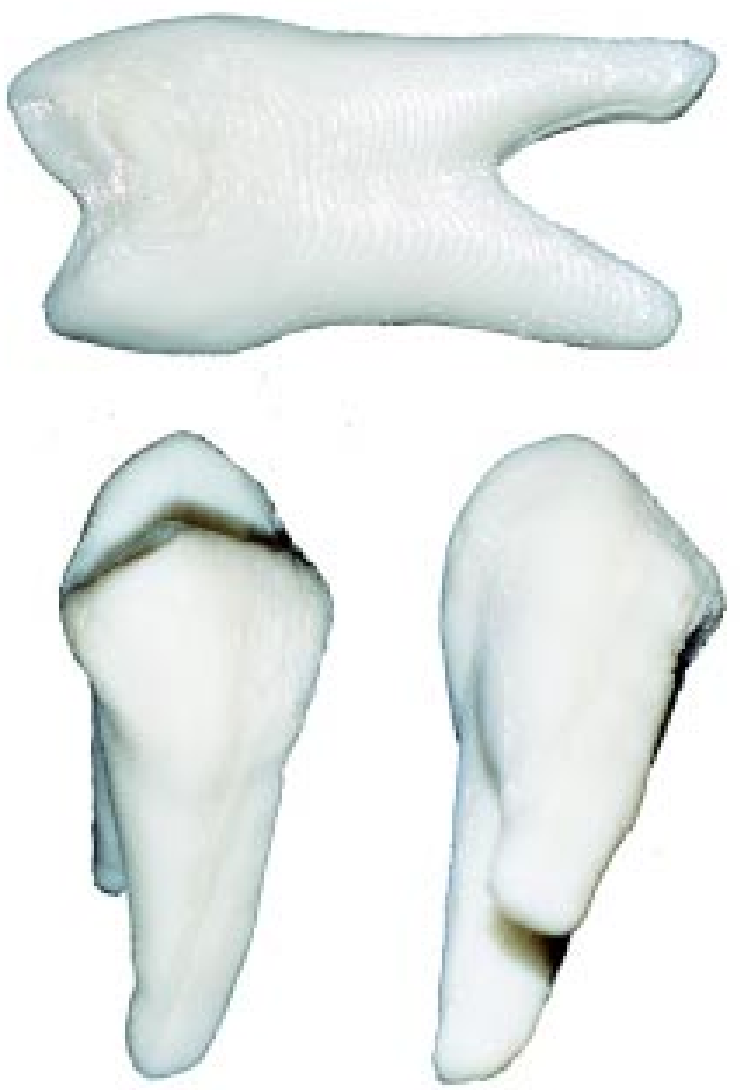

Fig. 3. Printed 3D macro models of a upper premolar tooth according to the scanning dataset.

\section{DISCUSSION}

The study of dental morphology is a basic and essentials theme in dental science, a component of the basic sciences in the program of Dentistry Schools and introduces students to the morphological characteristics of primary and permanent human dentition. It is very important for clinicians to understand dental form and internal structure in three dimensions. Various aspects of tooth geometry and size have been investigated for tooth forms (Kato \& Ohno, 2009).

The external anatomy of teeth should be very well known. Theoretical studies are not enough. The student should study the detailed description of the tooth with copies of them in their hands. Besides the study of extracted natural teeth, macro models made of plaster or resins and dental arch models help to understand the aspects that must be taught. Macro models facilitate the assimilation or re- memorization of anatomy because they show all anatomical details that need to be reproduced. In this way, the student who practices dental carving exercises is able to develop normal anatomical form of teeth, rees tablishing the function of the dental element.
Macro models allow a better visualization of the morphologic characteristics of permanent teeth and students of dental anatomy (Siéssere et al.)

Dental educators are responsible for providing the requisite psychomotor training to students during their preclinical education. Innovative strategies are needed to facilitate learning and motivate students' interest, as well as to help them visualize the tooth anatomy. Though currently the use of computers and computer assisted graphics have helped out in teaching dental anatomy in the three dimensional views, drawing and dental carving are considered to be very practical and objetive methods for teaching and motivating dental students to obtain the knowledge till today. Traditional classes suffer with the lack of possibilities for interaction, as they do not develop manual skills (Kataoka $e t$ al., 2005). Furthermore, several teaching institutions, with the purpose of developing psychomotor skills, have associated these classes with the activity of recognizing and reproducing dental morphology by examining samples of preserved teeth combined with the dental sculpture from wax blocks (Brueckner \& MacPherson, 2004; Siéssere et al.). With the purpose to achieve better understanding and visualization of dental morphology, macromodels are tools that have been proved to be efficient, both in this study and in others, as they are instruments that provide accurate anatomy (Buchaim $e t$ al., 2014).

With advances in three-dimensional (3D) measurement devices, geometric data can be obtained more rapidly. Analysis of morphology based on 3D information is efficient, as it enables morphometric evaluation of internal and external structure without sample destruction (Hannig et al., 2006, Kato \& Ohno).

The main advantage of virtual models is the facility of manipulation to change geometry by the software. It also allows rotation, fade in/fade out, cursor movements that reveal structures, etc. The versatility of these virtual models allows data exportation in other extension type, which enables communication with numerical simulation software, e.g., finite element analysis (Prado et al., 2013; Freire et al., 2014; Rossi et al., 2014) and biomechanical analysis (Soares et al., 2013). Thus, it can also be used in several classes at a dental school such as dental anatomy. The development of alternative methods, such as computer-graphics, to aid in teaching threedimensional dental anatomy and Tooth Morphology, which is a computer-assisted learning program designed to teach the anatomy of the adult dentition are important for motivating and teaching students. The Tooth Morphology program, in combination with interactive class meetings, has replaced traditional dental anatomy lectures; however, it does not replace the practice of dental sculpting (Siéssere et al.). 
Rapid prototyping (RP) is an expression that represents a technology based on the construction of physical three-dimensional structures, layer by layer, based on its respective virtual models (Soares et al., 2012). RP has become an innovative method of fast and cost-effective production of three-dimensional models for manufacturing. Wide access to advanced medical imaging methods allows application of this technique for dental training purposes. Four leading technologies are used for rapid prototyping (RP): stereoiithography, selective laser sintering (SLS), fused deposition modelling (FDM), and three-dimensional (3D) printing (Torres et al., 2011). Digitally prepared 3D objects are sent to the 3D printer like in an ordinary ink-jet desktop printer. The concept of printing is similar to that of a regular printer; The 3D printer can use various materials: high- performance composites are used to produce tough, strong, coloured, and best resolution models; elastomeric materials which give rubber-like properties or casting material which enables the creation of metal prototypes. 3D printers are characterised by their excellent speed: a hand-held part is produced within two or less hours (Torres et al.).

After being introduced in the biomedical area, computer-directed rapid prototyping techniques have been used for dental therapy, mainly for the fabrication of models to ease surgical planning and in implantology, orthodontics, and maxillofacial prostheses (Pozzer et al., 2013). Rapid prototyping technique can be also applied in another fields in undergraduate dental education. Chan et al. (2004) using mechanical computer-aided design systems and stereolithography machines, a geometric model of a teaching cube with tooth cavities was constructed. The authors conclude that the advantages of stereolithography are due to the capability of building complex geometrical accuracy and good surface finish. In this presented case of a teaching cube $(2.54 \mathrm{~cm} 3)$, the production time is usually thirty minutes and the cost is about $\$ 20$ each. Using this system, it is easy to create teaching blocks with a variety of type and number of cavities, their sizes, and their positions. These models are used in preclinical dental education for the development of student's visual recognition skills and fine eye-hand coordination. The authors found that the students could grasp the concepts of different types of cavity preparation more easily with this model in their hands during exercises and they could start to communicate and express themselves in terms of evaluations of the cavity preparations at an earlier time in the preclinical technique (Torres et al.).

The development of RP systems has led to the creation of customized three-dimensional anatomic models that exhibit a level of complexity unknown, primarily because RP methodologies use an additive process of building an object in layers defined by a computer model that has been virtually sliced (Nayar et al., 2015).

A disadvantage to visualize the data acquired and processed to $3 \mathrm{D}$ reconstruction, is that a $3 \mathrm{D}$ software and adequate hardware is required. But with 3D printing, all these complications disappear, and the generation of 3D models can be applied in any institution, without the need to mount a computer lab or have digital equipment so that all students can use.

It is important to continue searching for alternative and integrative teaching techniques, which allow for developing both basic and professional sciences. Virtual and printed teeth are intended to be a valuable learning tool that can be used in addition to or instead of extracted teeth and they are anticipated to represent an improvement over plastic teeth. The association of RP models with 3D- virtual models is a viable and accessible technique that helps and enriches the teaching-learning process.

CANTÍN, M.; MUÑOZ, M. \& OLATE, S. Generación de modelos de diente 3D basados en escaneo tridimensional para el estudio morfológico de dientes permanentes. Int. J. Morphol., 33(2):782-787, 2015.

RESUMEN: El estudiante de odontología debe tener un conocimiento profundo de la morfología dental y desarrollar la habilidad manual adecuada para reproducir cualquier parte del diente, manteniendo así la correlación perfecta con las estructuras asociadas. La tecnología se está convirtiendo en una parte integral de la educación y la práctica dental, especialmente por la generación de información en tres dimensiones y la producción de objetos sólidos a partir de modelos computadorizados. El objetivo fue desarrollar material educativo que permita al estudiante de odontología aprender a identificar fácilmente las características morfológicas de los dientes permanentes, utilizando las nuevas herramientas tecnológicas. Dientes permanentes sanos maxilares y mandibulares fueron digitalizados utilizando un escáner 3D HD NextEngine ${ }^{\mathrm{TM}}$ mediante sistemática MultiDrive. Una exploración de $360^{\circ}$ en rango macro fue elegido en cada caso. El número de escaneos para cada diente de 16, debido al nivel de detalle e irregularidades de las superficies dentarias que requieren lecturas de un mayor número de ángulos. Los volúmenes externos de los dientes escaneados fueron generados y almacenados en archivos *.STL. Las reconstrucciones generadas fueron transferidas para la producción de prototipos físicos que reproducen fielmente la anatomía de interés utilizando el programa ReplicatorG y la impresora Mbot Grid II 3D. Se obtuvieron modelos virtuales 3D y macro modelos impresoss en 3D de los dientes permanentes. Estos modelos permiten una excelente visualización de las características morfológicas. Los modelos dentarios virtuales e impresos en 3D, derivados de un diente real, son una valiosa herramienta de aprendizaje que se puede utilizar además de o en lugar de dientes extraídos, y representan una mejora anatómica sobre los modelos de dientes plásticos utilizados actualmente.

PALABRAS CLAVE: Morfología dental; Diente permanente; Educación dental; Escaneo 3D; Impresión 3D; Macro modelos. 


\section{REFERENCES}

Brueckner, J. K. \& MacPherson, B. R. Benefits from peer teaching in the dental gross anatomy laboratory. Eur. J. Dent. Educ., 8(2):72-7, 2004.

Buchaim, R. L.; Andreo, J. C.; Rodrigues, A. D.; Gonçalves, J. B. D.; Daré, L. R.; Rosa, G. M.; Buchaim, D. V. \& de Oliveira, J. A. Multidisciplinary Approach in the Teaching of Dental Sculpture and Anatomy. Int. J. Morphol., 32(2):399-403, 2014.

Chan, D. C.; Frazier, K. B.; Tse, L. A. \& Rosen, D. W. Application of rapid prototyping to operative dentistry curriculum. J. Dent. Educ., 68(1):64-70, 2004.

de Boer, I. R.; Wesselink, P. R. \& Vervoorn, J. M. The creation of virtual teeth with and without tooth pathology for a virtual learning environment in dental education. Eur. J. Dent. Educ., 17(4):191-7, 2013.

de Boer, I. R.; Lagerweij, M. D.; Wesselink, P. R. \& Vervoorn, J. M. Evaluation of the appreciation of virtual teeth with and without pathology. Eur. J. Dent. Educ., 19(2):87-94, 2015.

Freire, A. R.; Prado, F. B.; Rossi, A. C.; Noritomi, P. Y.; Neto, F. H. \& Caria, P. H. F. Biomechanics of the Human Canine Pillar Based on its Geometry Using Finite Element Analysis. Int. J. Morphol., 32(1):214-20, 2014.

Friedland, B.; Donoff, B. \& Dodson, T. B. The use of 3-dimensional reconstructions to evaluate the anatomic relationship of the mandibular canal and impacted mandibular third molars. J. Oral Maxillofac. Surg., 66(8):1678-85, 2008.

Hannig, C.; Krieger, E.; Dullin, C.; Merten, H. A.; Attin, T.; Grabbe, E. \& Heidrich, G. Volumetry of human molars with flat panelbased volume CT in vitro. Clin. Oral Investig., 10(3):253-7, 2006.

Kataoka, K.; Kobayashi, S.; Sato, T.; Soji, T.; Shioda, S.; Torigoe, K.; Matsumura, J.; Hisano, S.; Yasuda, Y. \& Suzaki, E. Anatomy education in medical and dental schools in Japan. Kaibogaku Zasshi, 80(2):41-7, 2005.

Kato, A. \& Ohno, N. Construction of three-dimensional tooth model by micro-computed tomography and application for data sharing. Clin. Oral Investig., 13(1):43-6, 2009.

Nayar, S.; Bhuminathan, S. \& Bhat, W. M. Rapid prototyping and stereolithography in dentistry. J. Pharm. Bioallied Sci., 7(Suppl 1):S216-9, 2015.

Pozzer, L.; Cavalieri-Pereira, L.; Olate, S.; Asprin, 1. \& de Moraes, M. The Use of Metil-metacrilate Guide Manufactured on Biomodel of Polyurethane for Late Treatment of Panfacial Fracture. Int. J. Odontostomat., 7(1):73-8, 2013.
Prado, F. B.; Noritomi, P. Y.; Freire, A. R.; Rossi, A. C.; Neto, F. H. \& Caria, P. H. F. Stress Distribution in Human Zygomatic Pillar Using Three-Dimensional Finite Element Analysis. Int. J. Morphol., 31(4):1386-92, 2013.

Rossi, A. C.; Freire, A. R.; Botacin, P. R.; Caria, P. H. F. \& Prado, F. B. Computer Graphics Applied to Anatomy: A Study of two Bio-CAD Modeling Methods on Finite Element Analysis of Human Edentulous Hemi-Mandible. Int. J. Morphol., 32(3):803-11, 2014.

Siéssere, S.; Vitti, M.; de Sousa, L. G.; Semprini, M. \& Regalo, S. C. Educational material of dental anatomy applied to study the morphology of permanent teeth. Braz. Dent. J., 15(3):23842, 2004

Soares, P. V.; de Almeida Milito, G.; Pereira, F. A.; Reis, B. R.; Soares, C. J.; de Sousa Menezes, M. \& de Freitas Santos-Filho, P. C. Rapid prototyping and 3D-virtual models for operative dentistry education in Brazil. J. Dent. Educ., 77(3):358-63, 2013.

Torres, K.; Staskiewicz, G.; Sniezynski, M.; Drop, A. \& Maciejewski, R. Application of rapid prototyping techniques for modelling of anatomical structures in medical training and education. Folia Morphol. (Warsz), 70(1):1-4, 2011.

\section{Corresponcence to: \\ Mario Cantín \\ Faculty of Dentistry \\ Universidad de La Frontera \\ Manuel Montt 112 \\ Temuco \\ CHILE}

Email: mario.cantin@ufrontera.cl

Received : 12-02-2015

Accepted : 25-03-2015 